\title{
ضوابط إسلامية
}

\section{في الأغراض الشعرية}

\section{* محمد رفعت أحمد زنجير}

مقدمة

الشعر وعاء للمعرفة العلمية والعواطف الإنسانية منذ القدم، وهو سلاح من أسلحة البيان ولعله أقواها وأمضاها، فنحن في أواخر القرن العشرين، ما زلنا نستشهد بأبيات من المعلقات على معنى نريده، ونترنم

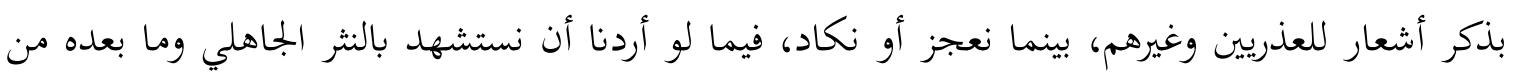
عصور، على معنى نطرقه، أو موضوع نعالجه، وذلك في المواطن التي يرتحل فيها الكلام، اللهم إلا أن يكون النص المراد حديثاً نبوياً، أو قولاً مأثوراً، أو خطبة ذائعة.

ومما يؤكد أهمية الشعر اتخاذه سلاحاً مشروعاً في مواجهة أعداء الدين في عهد النبوة. وقد استمرت هذه الوظيفة للشعر فيما تلا ذاك العصر من عصور، حتى العصر الحديث، فنجد شعر الجهاد وما أكثره في هذا العصر.2 ولعل السبب في ذلك هو ما تواجهه الأمة من تحديات على كافة الأصعدة: الثقافية والاجتماعية والاقتصادية والسياسية، ويأتي في مقدمة هذه التحديات قضية الاستقلال والتحرر السياسي من السيطرة الاستعمارية.

وفي ظل هذه التحديات الخطيرة، بدأت الأمة تستيقظ، وبدا الحس الإسلامي ينمو، وكانت ولادة الصحوة الإسلامية، فكان لا بد للمسلم من أن يربط نفسه بالإسلام وهو يتطلع إلى المستقبل، وأن تنشط

$$
\begin{aligned}
& \text { * دكتوراه في البلاغة والنقد من جامعة أم القرى، 1415هـ/1995م. أستاذ مساعد بقسم اللغة العربية، كلية معارف الوحي العلوم } \\
& \text { الإنسانية، الجامعة الإسلامية العالمية بماليزيا. }
\end{aligned}
$$

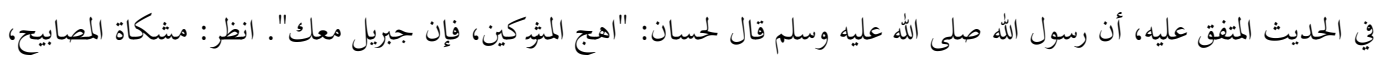

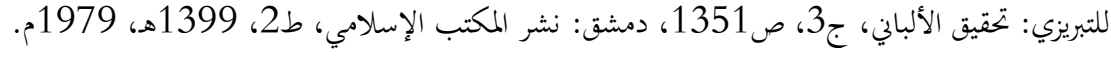

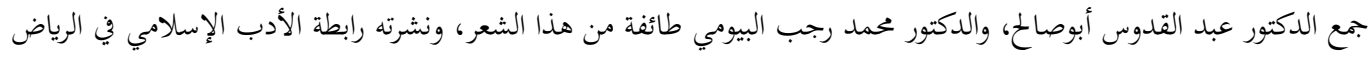

$$
\begin{aligned}
& \text { تحت عنوان: من شعر الجهاد في العصر الحديث، وهو منا يؤكد ما قلناه. }
\end{aligned}
$$


الثقافة الإسلامية وتنتعش من جديد، ويقوم الأدب بكهمته في هذه اليقظة، فلم يعد الحياد مع قضايا الأمة مقبولاً من الأديب، بل ينبغي أن ينصهر في همومها وآلامها، وأن تكون أشعاره أو آثاره الأدبية المختلفة تعبر عن هذا الانصهار، وتدلل عليه.

والانصهار في قضايا الأمة غير كاف وحده، ما لم يرافق ذلك أيضاُ: الفنية في التعبير والأداء، والانضباط بالقيم الشرعية، فلا بد من التكامل بين الشكل والمضمون. وهذا البحث هو خطوة لوضع تصور عام للضوابط الإسلامية للأغراض الشعرية، ولم نشأ أن نكتب عن موقف الإسلام من الشعر، لأن موقفه محدد وواضح في قوله صلى الله عليه وسلم: "هو كلام فحسنه حسن، وقبيحه قبيح".

وعلى هذا جرى العلماء وجمهور الأمة من إباحة الشعر الجيد، قال القرطبي: "قال أبو عمرو: ولا ينكر

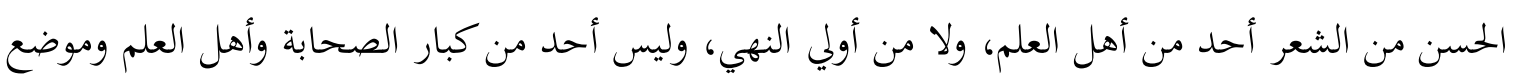
القدوة إلا وقد قال الشعر، أو تمثل به، أو سمعه فرضيه، ما كان حكمة أو مباحاً". 4 وقال العلامة الزبيدي: "الإنشاد والسماع جائزان بالإماع"، 5 وقال الحافظ ابن حجر: "يتحصل من كلام العلماء في حد الشعر الجائز أنه: إذا لم يكثر منه في المسجد، وخلا عن هجو، وعن الإغراق في المدح، والكذب المخض، والتغزل بمعين لا يحل. وقد نقل ابن عبد البر الإجماع على جوازه إذا كان كذلك". 6

بل إن تعلم الشعر مهم لإدراك بلاغة الكلام، وتذوق بلاغة القرآن، يقول الشيخ ابن عاشور: "ولم يزل العلماء يعنون بشعر العرب ومن بعدهم، وفي ذلك الشعر تحبب لفصاحة العربية وبلاغتها، وهو آيل إلى غرض شرعي من إدراك بلاغة القرآن".

$$
\begin{aligned}
& 3 \\
& 6 \\
& \hline
\end{aligned}
$$

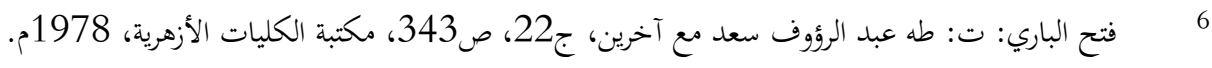$$
7
$$ 


\section{ما هي الأغراض الشعرية؟}

الأغراض التي يتناولها الشعراء كثيرة، والمعاني التي يطوقوها متشعبة، ولكن أشهر هذه الأغراض خمسة، وقد أشار إليها أبو هلال العسكري حين قال: "ولما كانت أغراض الشعراء كثيرة، ومعانيهم متشعبة جمة، لا يبلغها الإحصاء، كان من الوجه أن نذكر ما هو أكثر استعمالاً، وأطول مدارسة له، وهو: المدح والهجاء والوصف والنسيب والمراثي".

وهناك أغراض أخرى للشعر، ففي حماسة أبي تمام مثلاً نجد باباً في مذمة النساء، و وآخر للملح، والأخير موجود في الحماسة البصرية تحت عنوان الملح والمجون، 10 إلا أن هذه الأغراض ليس شائعة لدى جميع الشعراء، وليست أغراضاً رئيسة في الشعر، لذلك سنكتفي بالأغراض الخمسة الرئيسة التي سبق ذكرها، وهي: المديح والهجاء، والوصف، والنسيب، والمراثي. ونسعى إلى معرفة أهم الضوابط الشرعية لهذه الأغراض من خلال هذا البحث.

\section{أولاً - شعر المديح وموقف الإسلام منه}

المديح هو أكثر الأغراض الشعرية دوراناً في الشرع العربي، وقد ازدهر شعر المديح بسبب تشجي الخلفاء والأمراء والوزراء والقادة لمذا اللون من الشعر، ومنحهم الجوائز السنية لأربابه.

ويظن بعض الناس أن المديح يورث الرياء والخيلاء لدى الممدوح، ويضعف الإيمان لدى المادح، فيرفضون هذا اللون من الشعر.

$$
\begin{aligned}
& 8 \text { كتاب الصناعتين: بتحقيق علي محمد البجاوي، ومحمد أبوالفضل إبراهيم، ص131، صيدا: نشر المكتبة العصرية، 1406هـ، } \\
& \text { 1986م. } \\
& \text { شرح ديوان الحماسة المنسوب للمعري: ت: د. حسين محمد بقشة، ج2، ص1233، بيروت: دار الغرب الإسلامي، 1411هـ، } \\
& \text { 1991م. } \\
& 10
\end{aligned}
$$


وهناك من يذهب إلى أن المديح يورث فوائد بجة، 11 فأنت تشيد بالصفات الخيرة في الممدوح وتثبت دعائمها في نفسه، وكأنك هذا تدعو السامعين إلى الاقتداء به في مكارم الأخلاق، وفي هذا بعث لمشاعر التربية الاجتماعية، وتقوية للروابط الإنسانية.

والحق أن المديح لا يمكن قبوله مطلقاً، أو رفضه، وإنما لا بد من وضع ضوابط للقبول أو الرفض، وهو ما أشار إليها العلماء من قبل. 12 فالإمام الغزالي يرى أن هنالك آفات قد يقع بها المادح والممدوح على حد سواء. فالمادح قد يفرط فينتهي إلى الكذب، وقد يدخله الرياء فإنه بالمدح مظهر للحب، وقد يقول ما لا يتحققه ولا سبيل لاطلاع عليه، وقد يفرح الممدوح وهو ظالم فاسق. وفي مقابل هذا فإن الممدوح يضره المدح من وجهين، فقد يحدث فيه كبراً وإعجاباً وهما مهلكان، وقد يرضى بالمديح عن نفسه، ومن أعجب بنفسه لئه قلّ تشمره، وإنما يتشمر للعمل من يرى نفسه مقصراً 13 ثم يعقب على ذلك بقوله: "فإن سلم المدح من هذه لفه الآفات في حق المادح والممدوح لم يكن به بأس، بل ربما كان مندوباً غليه". 14

ويرى القرطبي أن الشعر الذي يتضمن ذكر الله وحمده والثناء عليه، أو ذكر رسول الله صلى الله عليه وسلم ومدحه والذب عنه ومدح أصحابه رضي الله عنهم مندوب إليه. يقول: "فأما ما تضمن ذكر الله وممده والثناء عليه فذلك مندوب إليه، كقول القائل:

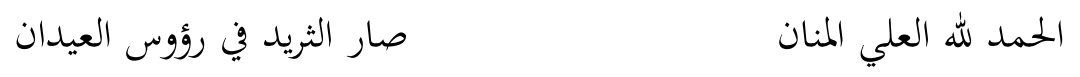

أو ذكر رسول الله صلى الله عليه وسلم، أو مدحه... أو الذب عنه، كقول حسان:

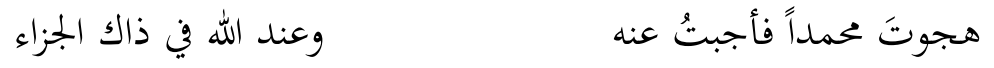

$$
\begin{aligned}
& 11 \text { انظر دفاع د. زكي مبارك عن شعر المديح في رده على أحمد أمين في كتابه: جناية أحمد أمين على الأدب العربي، بيروت: نشر دار }
\end{aligned}
$$

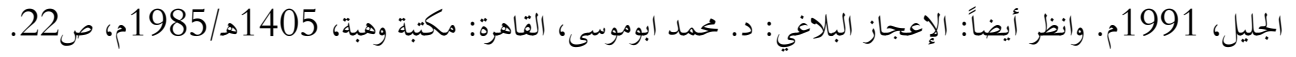

$$
\begin{aligned}
& 12 \\
& 1314 \\
& \text { 14 } 14
\end{aligned}
$$


وهي أبيات ذكرها مسلم في صحيحه، وهي في السير أتم... أو الصلاة عليه... وكذلك ذكر

أصحابه ومدحهم رضي الله عنهم". 15

والزخشري يرى توجيه المديح أيضاً إلى صلحاء الأمة، 16 ويرى النووي أن الشعر مستحب "إذا كان في

ممادح الإسلام وأهله، أو في هجاء الكفار والتحريض على قتاهيه ألم أو تحقيرهم ونحو ذلك". 17

ويباح للشاعر التوسع في المعاني، والذهاب في المبالغات، لأن هذا من سمات الشعر، يقول الإمام

الغزالي: "نعم مقصود الشاعر المدح والذم والتشبيب، وقد يدخله الكذب، وقد أمر رسول الله صلى الله عليه وسلم حسان بن ثابت الأنصاري بهجاء الكفار، والتوسع في المدح، فإنه وإن كان كذباً، فإنه لا يلتحق في

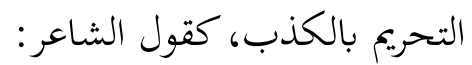

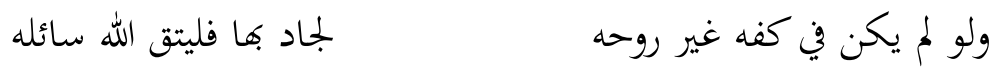

فإن هذا عبارة عن الوصف بنهاية السخاء، فإن لم يكن صاحبه سخياً كان كاذباً، وإن كان سخياً فالمبالغة من صنعة الشعر، فلا يقصد منه أن يعتقد صورته، وقد أنشدت أبيات بين يدي رسول الله صلى الله عليه وسلم لو تتبعت لوجد فيها مثل ذلك، فلم يمنع منه". 18 فكما نلحظ من كلام الغزالي أن ثمة فرق بين المبالغة، وهي أن يكون الممدوح شجاعاً مثلاً، فتشبهه بالأسد، لثثبت له كمال الشجاعة، وبين الكذب وهو أن يكون الممدوح جباناً، فتشبهه بالأسد، وتدعي له الشجاعة، أما المبالغة الأولى فلا مؤاخذة فيها، وهي من مقتضيات اللغة الشعرية، وأما الثانية ففيها مؤاخذة، 19 لأن الأديب المسلم يجب أن يتسامى عن قول الزور وتزييف الحقائق. ولهذا السبب نجد عمر بن

$$
\begin{aligned}
& 15 \text { 1 } 16
\end{aligned}
$$

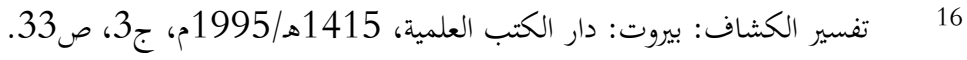

$$
\begin{aligned}
& 17 \\
& 18 \\
& 19 \text { انظر : فتح الباري، مصدر سابق، ج22، ص343. }
\end{aligned}
$$


الخطاب رضي الله عنه، يُعجب بشعر زهير، وينعته بأنه أشعر الشعراء "لأنه كان لا يعاظل في الكلام، وكان يتجنب وحشي الشعر، ولم يمدح أحداً إلا بما فيه". 20

فإذا كان زهير -وهو الشاعر الجاهلي- يلتزم بقيمة الصدق في شعره، مما أثار إعجاب عمر رضي الله عنه بشعره، فخليق بالشاعر المسلم أن يكون أكثر حرصاً على هذه القيمة العظيمة في شعره أيضاً، فلا يقلب حقائق الأمور، ولا يجعل من الصعاليك صناديد أو بالعكس، ابتغاء منفعة زائلة فلا بد من "إبعاد التكسب عن الأدب، مهما كانت الجهة التي يريد الأديب أن بتملقها، نظير دريهمات قليلة، أو شهرة زائلة، وهذا بطبيعة الحال على حساب الأهداف الحقيقية للشعر والنثر الفني". 21

وينبغي الحذر من الغلو في شخصية الممدوح، وإعطائها من المديح ما لا ينبغي لبشر، فقد وقع كثير من الشعراء في المخظورات الشرعية من حيث لا يعلمون نتيجة للإفراط في المديح، وهذه أمثلة لذلك:

$$
\begin{aligned}
& \text { فهذا هو العكوك (علي بن جبلة) الشاعر العباسي المعروف، يمدح أبا دلف الخزرجي قائلاً:22 } \\
& \text { كل من في الأرض من عرب بين بادية إلى حاضرة }
\end{aligned}
$$

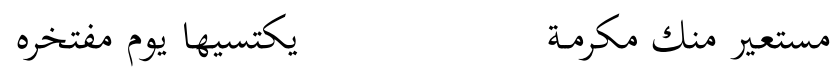

ذكر ابن خلكان أن الخليفة المأمون طلب العكوك لما قال هذين البيتين، "فلما صار بين يديه، قال له: يا ابن اللخناء، أنت القائل في قصيدتك للقاسم بن عيسى، وهو أبو دلف: كل من الأرض من عرب...

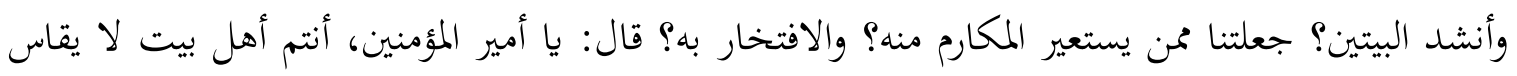
بكم، لأن الله اختصكم لنفسه عن عباده، وآتاكم الكتاب والحكمة، وآتاكم ملكاً عظيماً، وإنما ذهبت في قولي إلى أن أقران وأشكال القاسم بن عيسى من هذا الناس. فقال: والله ما أبقيت أحداً، ولقد أدخلتنا في الكل، وما استحل دمك بكلمتك هذه، ولكني أستحله بكفرك في شعرك، حيث قلت في عبد ذليل مهين، فأشركت بالله العظيم، وجعلت معه مالكاً قادراً، وهو:

$$
\begin{aligned}
& 20 \\
& 21 \text { 2. } 20
\end{aligned}
$$

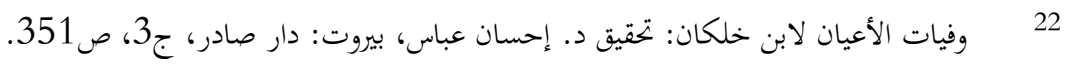




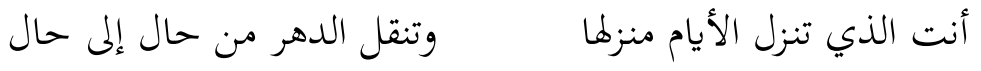

$$
\begin{aligned}
& \text { وما مددت مدى طرف إلى أحد إلا قضيت بأرزاق وآجال }
\end{aligned}
$$

ذاك الله عز وجل يفعله، أخرجوا لسانه من قفاه، فأخرجوا لسانه من قفاه فمات! وذلك في سنة

$$
\text { ثلاث عشرة ومائتين ببغداد". }
$$

$$
\text { وهذا ابن هانئ الأندلسي يقول لممدوحه : }
$$

$$
\text { ما شئت لا ما شاءت الأقدار فاحكم فأنت الواحد القهار }
$$

قال ابن خلكان: "وديوانه كبير، ولولا ما فيه من الغلو في المددح، والإفراط المؤدي إلى الكفر، لكان من

$$
\text { وأحسن الدواوين". } 24 \text { يا منا المتنبي يورد له ابن كثير قوله في بعض الملوك: } 25 \text { لألوذ به فيما أؤمله }
$$

وعقب على ذلك بقوله: "وقد بلغني عن شيخنا العلامة شيخ الإسلام أحمد بن تيمية رحمه الله أنه كان ينكر على المتببي هذه المبالغة في مخلوق، ويقول: إنما يصلح هذا لجناب الله سبحانه وتعالى. وأخبرين العلامة شمس الدين بن القيم رحمه الله، أنه سمع الشيخ تقي الدين المذكور يقول: ربما قلت هذين البيتين في السجود،

$$
\text { أدعو الله بما تضمناه من الذل والخضوع". } 26
$$

$$
\begin{aligned}
& 23 \\
& \text { 24 } \\
& 25 \text { البداية والنهاية: عتقيق د. أمدا أبوملحم وآخرين، بيروت: دار الكتب العلمية، 1409هـ/1989م، ج11، ص275. } \\
& 26
\end{aligned}
$$


هذه ليست إلا نماذج قليلة ما وقع به الشعراء في مخالفة الشارع، بسبب الغلو في أشخاص الممدوحين، وهو مما ترفضه الأذواق وتنفر عنه الفطرة السليمة، ولذلك أثار استياء الخليفة، وأهل العلم، فلا ينبغي رفع الممدوح أياً كان فوق ما يستحقه من رتبته البشرية، وعبوديته لله عز وجل.

ينبغي أيضاً تقديم الفضائل الإنسانية والدينية على الفضائل الجسمية والمادية للممدوح. فتكون الإشادة بعدله لا بجسمه، وبعطائه لا بقصره، لأن الأمور المادية من سلطان ومال وجمال ليست هي موضع التفاضل الحقيقي بين الناس، وإنما التفاضل فيما يؤتيه الله لكل واحد منهم من علم وحكمة، وما يوفقه إليه

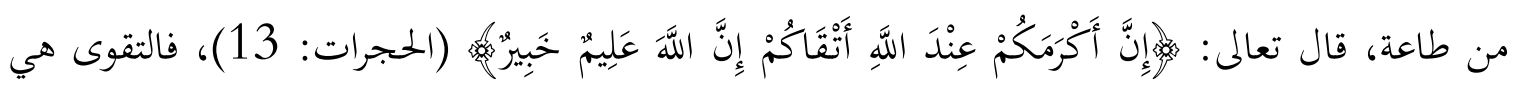
المعيار الحقيقي للتفاضل في التصور الإسلامي. وقد تنبه لذلك عبد الملك بن مروان حين مدحه ابن قيس

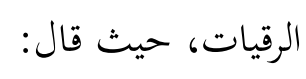

على جبين كأنه الذهب يأتلق التاج فوق مفرقه فغضب عبد الملك وقال: "قد قلت في مصعب: هـ بتحلت عن وجهه الظلماء إنما مصعب شهاب من اللا

فأعطيته المديح بكشف الغمه، وجلاء الظلم، وأعطيتني من المدح ما لا فخر فيه، وهو اعتدال التاج فوق جبيني، الذي هو كالذهب في النضارة". 27 هذه رواية أبي هلال للقصة. ورواها المرزباني بدون الزيارة الأخيرة، حيث جاء فيها أن عبد الملك قال بعد أن ذكر بيت مصعب: "وأما لي: فتقول: على جبين كأنه

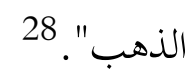


وقد أعقب المرزباني على هذا الخبر في موضع آخر من كتابه حيث قال: "فوجه عيب عبد الملك إنما هو من أجل أن هذا المادح عدل به عن الفضائل النفسية التي هي العقل، والعفة، والعدل، والشجاعة، وما جانس ذلك ودخل في جملته، إلى ما يليق بأوصاف الجسم في البهاء والزينة، وذلك غلط وعيب". 29 هذا هو اجتهاد العلماء في هذه الحمادثة. ولا يبعد أن يكون عبد الملك كان يرى في مديح مصعب بعداً دينياً عند قول الشاعر: "شهاب من الله" والشهاب من الله يدل أن له مهمة وهدف، فيرسله الله على رؤوس الشياطين من أعدائه، وفي هذا تزكية له وأية تزكية! وفي هذا تعريض بأعداء الدولة الزبيرية... ولعل عبد الملك كان يتوق لمثل هذا المديح.

يفضل عدم الإكثار من التشبيهات بالحيوانات والجمادات، وأن يكون تركيز الشاعر واهتمامه منصباً على الرقي بالممدوح، وإلحاقه بأهل الدرجات العلا، لا بوحوش الغابات التي ينهكها الجوع والسعي! قال أبو هلال: "وقد أنكر عبد الملك ما أنكره الأعرابي من تشبيه الممدوح بالأسد والصخر والبحر، ... قال عبد الملك يوماً وقد اجتمع الشعراء عنده: تشبهوننا بالأسد، والأسد أبخر. والبحر، والبحر أجاج. وبالجبل، والجبل أوعر. ألا قلتم كما قال أيمن بن خريم في فاتك بني هاشم:

$$
\text { فاركم مكابدة وصوم }
$$

لقد فطن عبد الملك وهو من هو في تذوق الشعر ونقده!، إلى ضرورة التجديد في لغة الشعر، والانعتاق من أسر الطريقة الجاهلية في المديح، ليكون المدح منصباً على المعايير الحقيقية التي يتفاضل فيها الناس، وهي: طول الصوم والجهاد في النهار، وطول القيام والعبادة في الليل... ومثل هؤلاء الذين يتصفون بهذه الصفات هم سادة الناس، ولا يستوي بهم غيرهم.

$$
29 \text { 30 } 30
$$


يحسن إكرام الشعراء إذا لم يكونوا يتاجرون بالكلمة، وقدر روي أن رسول الله صلى الله عليه وسلم خلع على كعب بن زهير بردته الشريفة، 31 وهذه سنة حسنة. فالإكرام هو تشجيع لعمل العقل. وحث على رونى تطوير اللغة الشعرية بما يخدم أهداف الدين الحنيف، مما يسهم في تطور الأمة، والمحافظة على لغتها الحية المتجددة، والحفاظ على اللغة أساس الحفاظ على الدين الحنيف. يقول الشيخ محمد الطاهر بن عاشور:

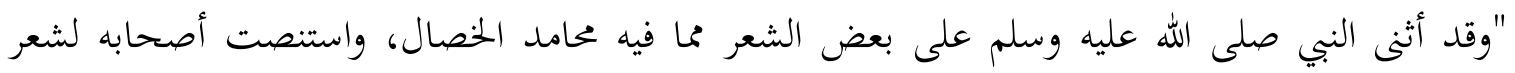
كعب بن زهير، مما فيه دقة صفات الرواحل الفارهة، على أنه أذن لحسان في مهجاة المشركين، وقال له: كلامك أشد عليهم من وقع النبل. وقال له: قل ومعك روح القدس... وأجاز عليه كما أجاز كعب بن زهير فخلع عليه بردته".

ولكن كيف يتفقه هذا مع قول النبي صلى الله عليه وسلم" :إذا رأيتم المداحين فاحثوا في وجوههم

لقد أجاب عن هذا العلماء، قال الخطابي: "المداحون هم الذين التخذوا مدح الناس عادة، وجعلوه بضاعة، يستأكلون به الممدوح. فأما من مدح الرجل على الفعل الحسن والأمر الممدوح، يكون منه ترغيباً له في أمثاله، وتريضاً للناس على الاقتداء في أشباهه فليس بمداح". 34

وقال البغوي: "المدح والثناء على الرجل مكروه، لأنه قلما يسلم المادح عن كذب يقوله في مدحه، وقلما يسلم الممدوح عن عجب يدخله". 35 والتوفيق بين ما قاله الخطابي والبغوي يكون بحسب الغرض من المديح، فإذا كان الغرض نيل المال، ولو بقول الزور، فهذا مرفوض.

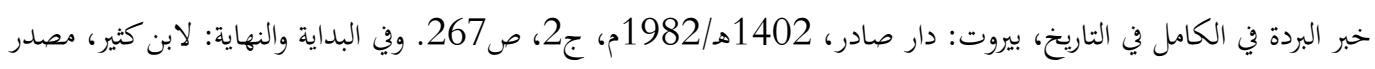

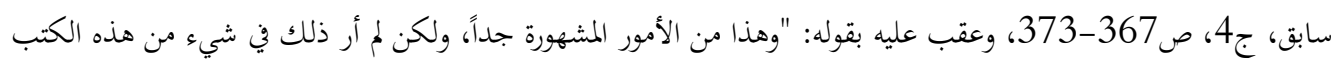

$$
\begin{aligned}
& \text { المشهورة بسند أرتضيه، والله أعلم". } \\
& 32
\end{aligned}
$$

33

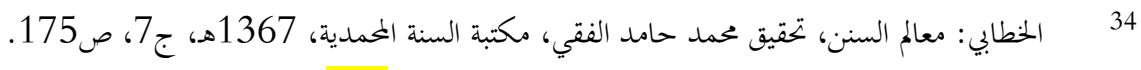

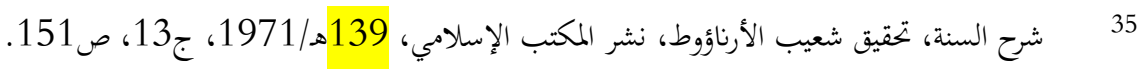


وإذا كان الهدف مشوباً. كإرضاء الممدوح، ونيل الحظوة، وإرساء الفضائل الخلقية من خلال ذلك.

$$
\text { فهذا فيه ما فيه، 36 وفي أحسن حالاته يكون مكروهاً. }
$$

وأما إذا كان الغرض وجه الله، وتشجيع الممدوح على السير في طريق الخير، والإشادة بالقيم الإنسانية العليا، فهذا هو السائغ المقبول. وفي هذا الإطار كانت مدائح حسان وكعب وابن رواحة لنبي صلى الله عليه وسلم، يقول عبد الله بن رواحة رضي الله عنه: 37

إذا انشق معروف من الفجر ساطع وفينا رسول الله يتلو كتابه إذا استثلت بالكفرين المضاجع يبيت بجافي جنبه عن فراشه به موقنات أن ما قال واقع أرانا الهدى بعد العمى فقولبنا إلى الله مششور هناك فراجع وأعلم علماً ليس بالظن أنني ويقول كعب بن مالك رضي الله عنه:38 بلسان أزهر طيب الأثواب ومواعظٍ من ربنا فُمدى بها من بعدما عرضت على الأحزاب عرضت علينا فاشتهينا ذكرها حرجاً ويفهمها أولو الألباب حكماً يراها المجرمون بزعمهمم

ففي هذه الأبيات اعتداد بصحبة النبي صلى الله عليه وسلم والاقتداء به، والفرح بما أنعم الله به على المؤمنين من نعمة الإسلام التي حرم منها الكفار بسبب جهلهم وغوايتهم. ونلحظ في شعر حسان رضي الله عنه شيئاً كثيراً من هذا، من ذلك قوله:39

36 ذهب البيضاوي إلى ضرورة إعطاء المادح ما طلب. جاء في فتح الباري: ج22، ص270، "المراد بكثو التراث في وجه المادح إعطاؤه ما طلب، لأن كل الذي فوق التراب تراب، وبهذا جزم البيضاوي".

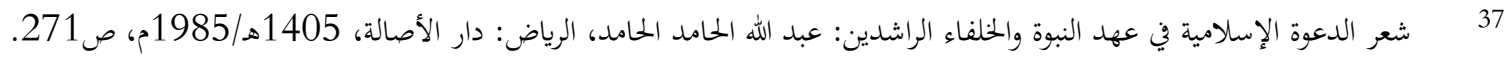

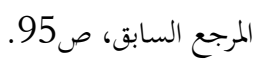




$$
\begin{aligned}
& \text { قد بينوا سنة للناس تتبع } \\
& \text { إن الذوائب من فهر وإخوقم } \\
& \text { تقوى الإله وبالأمر الذي شرعوا } \\
& \text { يرضى بها كل من كانت سريرته } \\
& \text { حاولوا النفع في أشياعهم نفعوا } \\
& \text { قوم إذا حاربوا ضروا عدوهم أو } \\
& \text { لا يطيعون ولا يرديهم الطمع } \\
& \text { أعفة ذكرت في الوحي عفتهم } \\
& \text { ومن عدو عليهم جاهد جدعوا } \\
& \text { كم من صديق لهم نالواكرامته } \\
& \text { فما وفن نصرهم عنه وما نزعوا } \\
& \text { أعطوا نبي الهدى والبر طاعتهم } \\
& \text { أو قال عوجوا علينا ساعة ربعوا } \\
& \text { إن قال سيروا أجدو السير جهدهم } \\
& \text { ولا ين همك الأمر الذي منعوا } \\
& \text { خذ منهم ما أتى عفواً إذا غضبوا } \\
& \text { شراً يخاض عليه الصَّاب والسَّلع } \\
& \text { فإن في حربهم فاتركن عداوتمم } \\
& \text { إذا تفرقت الأهواء والشيع } \\
& \text { أكرم بقوم رسول الله شيعتهم }
\end{aligned}
$$

فالشاعر هنا يشيد بالصحابة رضي الله عنهم لما كانوا عليه من منهج واضح، واتباع النبي صلى الله عليه وسلم، وباتصافهم بالقيم العليا من شجاعة، وكرم، وصبر، ووفاء، وبأس، ولا عجب في ذلك طالما أفم جند الله وأتباع رسوله الكريم، بينما يتبع غيرهم أهواءهم ويعبدون طواغيتهم.

ويمكن أن نعتبر شطراً من الشعر العربي كان يسير في هذا الاتحاه، ومن أجمل المديح وأصدقه قول الفرزدق في مدح زين العابدين بن علي بن الحسين، حين سئل عنه هشام ابن عبد الملك، فقال: لا اعرفه، فقال الفرزدق أنا أعرفه، تم أنشد: 40

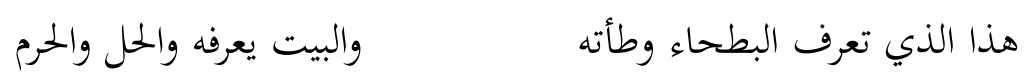

$$
39 \text { 30 } 30
$$


هذا التقي النقي الطاهر العلم

بجده أنبياء الله قد ختموا

$$
\text { العرب تعرف من أنكرت والعجم }
$$

يُستو كفان ولا يعروهما عدمُ

يزينه اثنان: حسن الخلق والشيم

حلو الشمائل تحلو عنده نعم

لولا التشهد كانت لاؤه نعم
هذا ابن خير عباد الله كلهم

هذا ابن فاطمة إن كنت جاهله

وليس قولك من هذا بضائره

كلتا يديه غياث عم نفعهما

سهلُ الخليقة لا تخشى بوادره

حمال أثقال أقوام إذا افتدحوا

ما قال لا قط إلا في تشهده

$$
\text { والقصيدة طويلة، وهي من غرر القصائد في الشعر العربي. }
$$

وما قدمناه ليس أكثر من مجرد نماذج لما يصلح أن يكون عليه شعر المديح، من حيث الإشادة بالقيم العليا التي يكون عليها الممدوح، بعيداً عن الأطماع الشخصية، وقد أثنى الرسول المعلم صلوات الله وسلامه عليه على بعض أصحابه، وعلى بعض أزواجه، وعلى بعض القبائل. وهو صلى الله عليه وسلم إمام في قوله وفعله، كما أنه صلى الله عليه وسلم قبل ثناء الشعراء وأجازهم، وقصارى القول في هذا قوله عليه الصلاة والسلام: 》لا تطروين كما أطرت النصارى ابن مريم، فإنما أنا عبده، فقولوا: عبد الله ورسوله《. 41

فمحبة الرسول صلى الله عليه وسلم وتوقيره والرفع من شأنه عمل جليل، ما لم يتجاوز ذلك حد المعقول. ولذلك علق العلامة علي القاري على هذا الحديث بقوله: "أي مثلٍ إطرائهم إياه، مفهوم أن إطراءه من غير جنس إطرائهم جائز". 42 وإذا كان الإطراء جائزاً بالحد المعقول بكق النبي صلى الله عليه وسلم، فهو جائز بكق الصحابة والصالحين والقادة والفاتحين، ضمن الضوابط التي ذكرناها. وذهب الإمام النووي إلى

$$
\begin{aligned}
& 41
\end{aligned}
$$

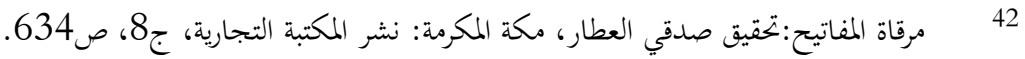


استحباب الدعاء لمن قال شعراً يمدح فيه أهل الإسلام ويذم أعداءهم. 43 وهذا مما يؤكد أهمية هذا اللون من

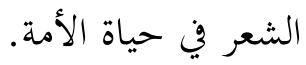

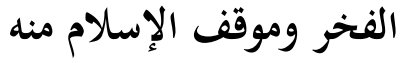

الفخر هو أحد أغراض الشعر، ويمكن أن يدرج تحت شعر المديح، لأنه مديح للنفس، وقد عرفه أبو هلال العسكري بقوله: "هو مدحك نفسك بالطهارة والعفاف والحلم والعلم والحسب وما يجري مجرى ذلك".

ولا ريب أن مديح النفس ليس ديدن المسلم الذي يتواضع لله سبحانه وتعالى، وذلك إذا كان هذا المديح بقصد الرياء والسمعة، والتعالي والتباهي، فما أبعد المسلم عن هذا كله، فقد ورد عن النبي صلى الله عليه وسلم" :لينتهين أقوام يفتخرون بآبائهم الذين ماتوا، إنما هم فحم من جهنم". 45 ولكن قد يكون الافتخار مطلوباً، وذلك في موطن الحرب، أو لإظهار نعم الله عز وجل والتحدث بها. وقد ورد عن الإمام البغوي قوله: "الافتخار والاعتزاز المنهي عنه ما كان في غير جهاد الكفار، وقد رخص النبي صلى الله عليه وسلم الخيلاء في الحرب مع هيه عنها في غيرها، وروي أن علياً رضي الله عنه بارز مرحباً

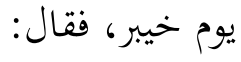

$$
\text { "أنا الذي سمتني أمي حيدرة". }
$$

وقال العلامة الطبيي: "لمفاخرة نوعان: مذمومة ومحمودة، فالمذموم منها ما كان عليها الجاهلية من الفخر بالآباء والأنساب للسمعة والرياء، والمحمود منها: ما ضم مع النسب الحسب في الدين لا رياءً، بل

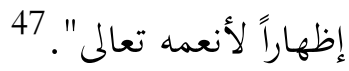

$$
\begin{aligned}
& 43 \\
& 44 \\
& 45 \text { من حديث رواه الترمذي وأبوداود عن أبي هريرة بإسناد حسن. انظر مشكاة المصابيح، ج3، ص1373. }
\end{aligned}
$$

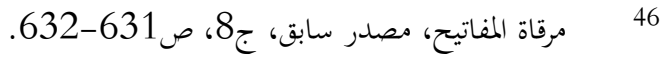

$$
\begin{aligned}
& 47
\end{aligned}
$$


ويؤيد ما ذهب إليه العلماء أن النبي صلى الله عليه وسلم في يوم حنين، غشيه المشركون، فنزل عن

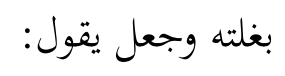

$$
\text { أنا النبي لا كذب أنا ابن عبد المطلب }
$$

$$
\text { قال البراء: "فما رئي من الناس يومئذ أشد منه". } 48
$$

إذاً ليست هنالك مشكلة بتعلنا نرفض هذا الشعر، طلما أنه في إطار الوضعية التي أرادها الشرع

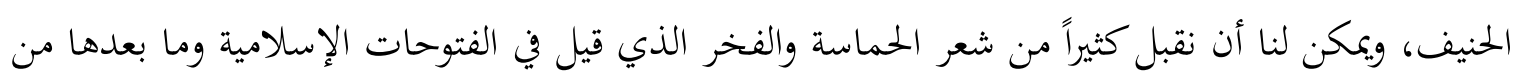

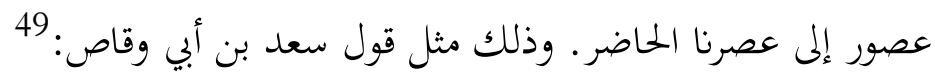

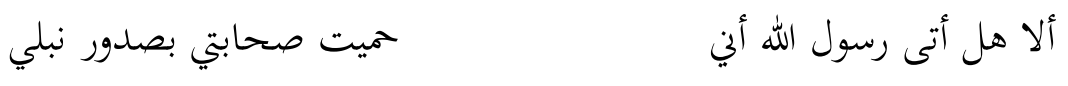

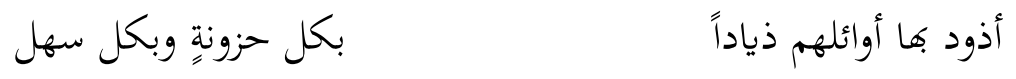

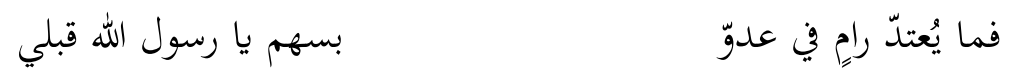

$$
\begin{aligned}
& \text { وذلك أن دينك دين صدق }
\end{aligned}
$$

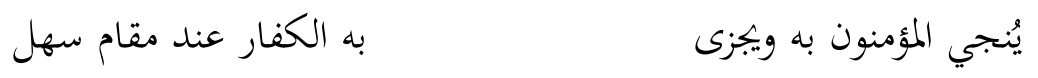

ومن شعر الفخر الذي ينسجم مع الدين الحنيف كثير من روميات أبي فراس الحمداني، ومنها قوله:50

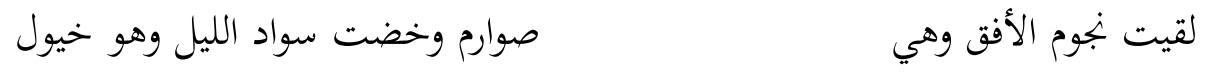

$$
\begin{aligned}
& \text { ولم أرع للنفس الكريمة خلة عشية لم يعطف علي خليل } \\
& \text { ولمكن لقيت الموت حتى تركتها وفيها وفي حد الحسام فلول }
\end{aligned}
$$

48 


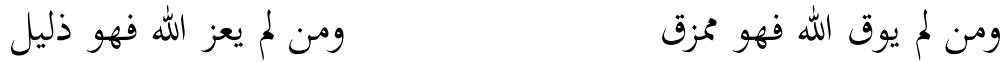

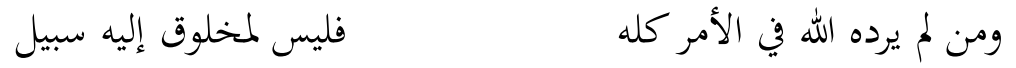

فانظر إلى اعتداد الشاعر بنفسه وشجاعته وإقدامه في الحرب، وذاك نابع كله من إمانه بالله عز وجل، وأن الله بيده مقاليد الأمر كله، وعليه وحده الاتكال. وهذا مما ينسجم مع العقيدة الإسلامية، بل هو نابع

\section{ثانياً - شعر الهجاء وموقف الإسلام منه}

الهجاء ضد المديح، قال قدامة: "فكلما كثرت أضداد المديح كان أهجى له" 51 ومذهب الشعراء في الهجاء ذكره ابن رشيق القيرواني، فقال: "وجميع الشعراء يرون قصر الهجاء أجود، وترك الفحش فيه أصوب إلا جريراً". 52 والمفضل في الهجاء عند الأدباء أن لا يهجو المرء الصفات الجسدية، وقد أشار إلى ذلك أبو هلال العسكري حين قال: "والاختيار أن ينسب المهجو إلى اللؤم والبخل واشره، وما أشبه ذلكن وليس بالمختار في الهجاء أن ينسب إلى قبح الوجه، وصغر الحجم، وضؤولة الجسم، يدل على ذلك قول القائل:

$$
\begin{aligned}
& \text { فقلت لها ليس الشحوب على الفتى بعارٍ ولا خير الرجال سمينها } \\
& \text { وقول الآخر: } \\
& \text { تنال الخير ممن تزدريه و يخلف ظنك الرجل الطرير"53 } \\
& \text { محموداً، ويسبب اللغو وعثرات اللسان. }
\end{aligned}
$$

ولا شك أن ما ذهب إليه جمهور الشعراء من قصر الهجاء هو الصواب، فالتمادي في الهجاء ليس

$$
\begin{aligned}
& 51
\end{aligned}
$$

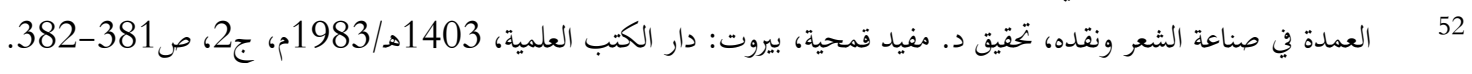

$$
\begin{aligned}
& 53
\end{aligned}
$$


وكذلك الأمر بشأن الاقتصار على الصفات النفسية دون الجسمية، لأن المرء لا يتحكم بشكله وجسمه، وإنما هو من صنع الله الذي أتقن كل شيء خلقه، ولكن يستطيع التحكم بغرائزه، وأفعاله التي هي محل المؤاخذة والتفاضل بين الناس، فما ذنب جحظة مثلاً حين هجاه ابن الرومي بقوله:54

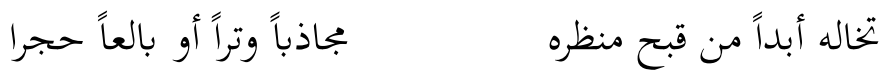
وقبل تحديد الضوابط الشرعية لهذا الغرض لا بد من الإشارة إلى أن الدين الحنيف رخص في هذا اللون من الشعر عند الضرورة، وليس مطلقاً. قال الفخر الرازي: "إن الله تعالى لما وصف الشعراء بهذه الأوصاف

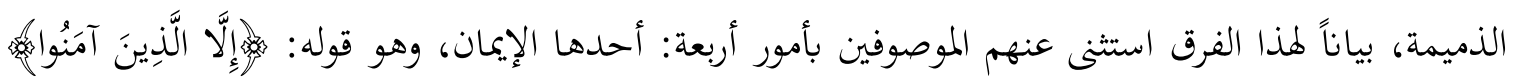

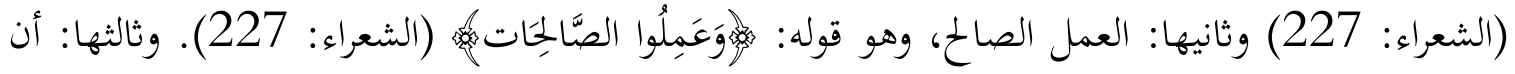

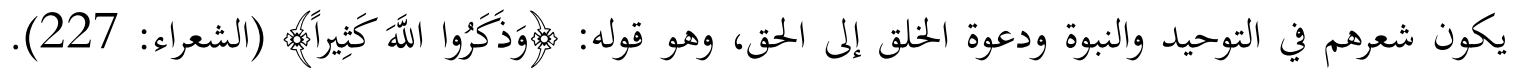

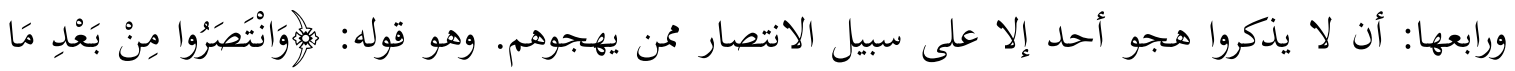

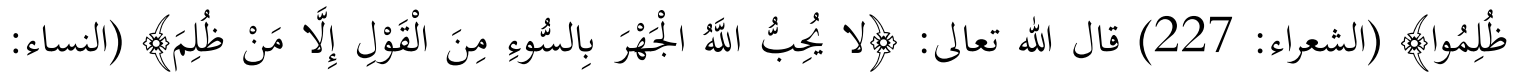

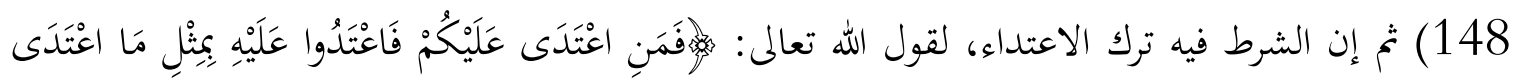
عَلَيْكُمْهُه. (البقرة: 194)" 55

وقال الدكتور الزحيلي: "فإن كان -لشعر - انتصاراً ممن هجا المسلمين، وشبب بأعراضهم جاز". 56

فالهجاء جائز لرد العدوان، ولأهل البغي والفسق الذين يعلنون العداوة لهذا الدين. كما يجوز الهجاء لشريحة من المجتمع المسلم من أهل البدع والفسق، ممن يجاهرون بذلك، وذلك "كالمخنث، وصاحب الماخور، والمجاهر بشرب الخمرة، ومصادرة الناس، وكان ممن يتظاهر به، بحيث لا يستنكف من أن يذكره له، ولا يكره أن يذكر به".

$$
\begin{aligned}
& \text { 54 } 5 \text { ديوان ابن الرومي: تحقيق د. حسين نصار، ج3، ص1092. } \\
& 55 \text { } 56
\end{aligned}
$$

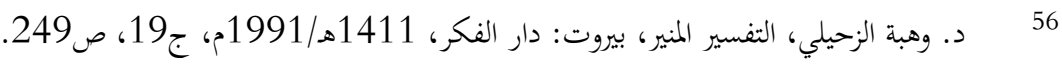

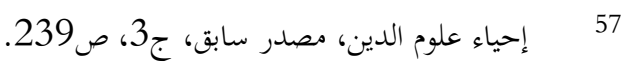


وينبي في الهجاء تجنب ذكر المعايب الجسمية، والألفاظ البذيئة، تناغماً مع آداب الإسلام وانسجاماً مع مقاصده، واقتصاره على شرائح معينة لا يتعداها، وذلك أن هجاء عامة المسلمين أو الدهر أو الزمان يتناف مع خلق الإسلام، ويجب على الحاكم المسلم محاسبة أولئك الذين يهجون الناس بدون سبب شرعي، كما فعل عمر رضي الله عنه مع الحطيئة حين سجنه لما هجا الزبرقان بن بدر، ثم خلى سبيله "وأخذ عليه ألا يهجو أحداً، وجعل له ثلاثة آلاف درهم اشترى بها منه أعراض المسلمين". 58 فليست أعراض المسلمين وعيوبهم موضعاً للتندر والسخرية والاستهزاء كما نراه في برامج التلفاز، فذاك هو غاية الإثم. وقد قال رسول الله صلى الله عليه وسلم لعائشة رضي الله عنها حين وصفت صفية بأغما قصيرة: 》القد قلت كلمة لو مزج بها البحر لمزجته!《. 59 يستحب هجاء الكفر وأعمال الكفار، لكي يرتدعوا ويفكروا لعلهم يرجعون إلى الرشد، وقد أمر الرسول صلى الله عليه وسلم حسان بذلك. 60 وأكثر ما يستحب هذا المجاء عند الحرب، ولكن يجب ألا ئل يشوبه الافتراء على الكفار بأهم فعلوا شيئاً معيناً وهم لم يفعلوه، فالمؤمن لا يعرف إلا الصدق. وما أحسن قول حسان رضي الله عنه يخاطب أبا سفيان، ويذود عن النبي صلى الله عليه وسلم، وهو مما يعد مثلاً يُجتذى لِّى في الهجاء المهذب اللاذع، وذلك قوله:61 61

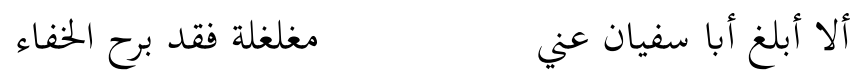

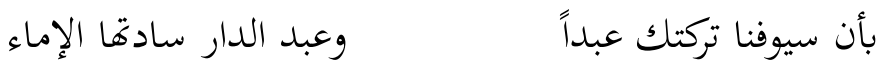

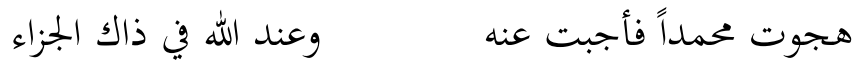
أقجوه ولست له بكفء ل

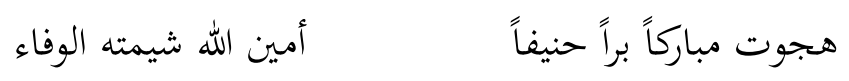

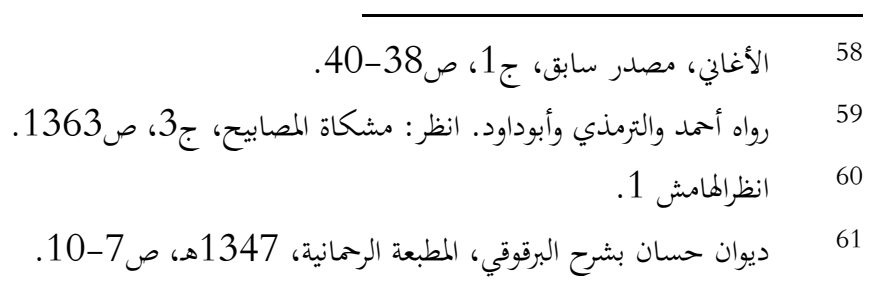




$$
\text { فمن يهجو رسول الله منكم ويمدحه وينصره سواء }
$$$$
\text { المراد بالوصف كما ذكر ابن قدامة: "ذكر الشيء كما فيه من الأحوال والهيئات".62 }
$$

والأشياء التي يصفها الشعراء كثيرة، فكل ما حولهم من الطبيعة والناس والأشياء يمكن لهم أن يصفوها

$$
\text { في أشعارهم. }
$$

وأجود الوصف هو "ما يستوعب أكثر معاني الموصوف، حتى كأنه يصور الموصوف لك، فتراه نصب

$$
\text { عينيك". }
$$

والوصف يمكن أن يؤدي غرضاً إسلامياً إذا التفت الشاعر إلى آثار قدرة الله المبدعة في صنع الأشياء،

$$
\text { فالكون كتاب صامت، وفي كل شيء آية تدل على الموجد المبدع، كما قال أبو العتاهية:64 }
$$

ووظيفة الشاعر أن ييرز الآيات للناس، من خلال هذه الكائنات الجميلة التي أبدعها الخالق عز وجل، وذلك مثلما فعل أبو العلاء المعري حين وصف الديك، وبين ما لهذا المخلوق الجميل من خصائص ومزايا... منها أنه دعامة للدين الحنيف حين يذكر الناس بأداء الصلاة. يقول:65

$$
\text { أيا ديك عدت من أياديك صيحة بعثت بها ميت الكرى وهو نائم }
$$

$$
\begin{aligned}
& 62 \\
& 63 \\
& 64
\end{aligned}
$$

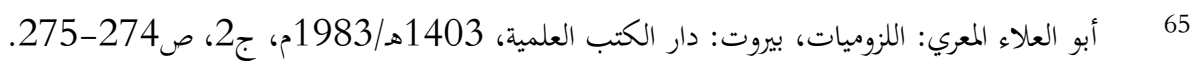




$$
\begin{aligned}
& \text { بها رئمتك العاطفات الروائم } \\
& \text { عليك ثياب خاطها الله قادراً } \\
& \text { يباهي به أملاكه ويوائم } \\
& \text { وتاجك معقود كأنك هرمز } \\
& \text { كلمعة برق مالها لدهر شائم } \\
& \text { وعينك سقط ما خبا عند قرة } \\
& \text { إذا قربت للموقدين الهشائم } \\
& \text { وما افتقرت يوماً إلى موقد لها } \\
& \text { أوان ترقت في السماء النعائم } \\
& \text { ورثت هدى التذكار من قبل جرهم } \\
& \text { إذا قلقت من حامليه الدعائم } \\
& \text { وما زلت للدين القديم دعامة }
\end{aligned}
$$

ومن أحسن الوصف ما فيه استكشاف للحقائق بين بواطن الأشياء، ومن ذلك قول ابن الرومي في

$$
\text { العلاقة بين السيف والقلم:66 }
$$

$$
\text { كالموت والموت لا شيء يغالبه }
$$

فالقلم كناية عن صاحبه وهو الكاتب العالم، والسيف كناية عن السلطان الغالب، وإذا كان صاحب القلم يأتمر بأمر صاحب السيف، فهذا لا يعني أفضلية الثاني على الأول، لأن القضاء الأزلي جرى بالقلم، وكل ما يجري في الوجود تبع لما خطه القلم الأول، ويكفي بهذا فضيلة للقلم على السيف!

$$
\begin{aligned}
& \text { وفي الموضوع ذاته يقول أبو الفتوح البستي:67 }
\end{aligned}
$$

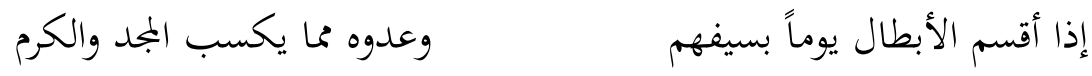

$$
\begin{aligned}
& 66 \text { } 67 \text { السيد أمد الهاشمي: جواهر الأدب، دار الفكر، ج2، ص326. }
\end{aligned}
$$

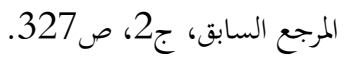


كفى قلم الكتاب عزاً ورفعة مدى الدهر أن الله أقسم بالقلم

فوصف هذه الكائنات، بما يملأ القلب خشوعاً وخضوعاً لله عز وجل، هو من صميم عمل الشاعر المسلم؛ كما يجدر بالشاعر المسلم أن يراعي ما يلي:

أن يجعل ما يصفه من قصور وعمران أنموذجات للآخرة، فلا يفتتن بها أو يفتن بجمالها الناس، وإنما يتذكر دوماً أن هذه الدنيا درا ابتلاء، وأن النعيم الكامل في دار الخلود، فعلى الناس أن تشد عزائمها، وتسعى في طلب الجمال الخالد في مقعد صدق عند مليك مقتدر، وهو ما صنعه البحتري عندما وصف رك رك بعض قصور المتوكل، ثم أعقب الوصف بقوله:68

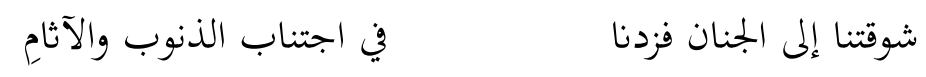

ألا يصف الأشياء المحرمة وصفاً يغري بها، مثل الخمر التي غرق في حبها بعض الشعراء، ووصفوها وصفاً يشجع الناس على كرعها والعياذ بالله تعالى. بل يجب أن يصفها وصفاً ينفر منها، فمن الوصف الأثيم للخمر قول ابن الرومي:69

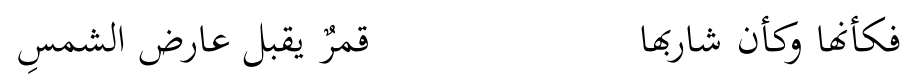

ومن الوصف الذي ينفر منها، ويتفق مع الشريعة السمحاء، ورسالة الأديب المسلم، قول أبي العلاء:70

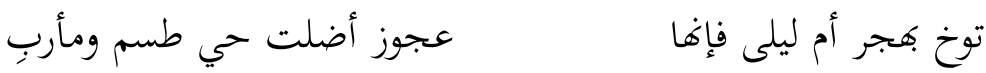

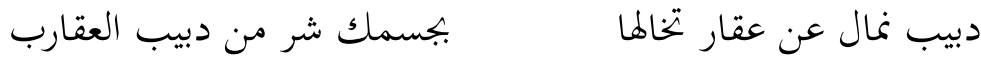

$$
\begin{aligned}
& \text { ولو أها كالماء طلق لأوجبت الصاها أصيلات النهى والتجارب }
\end{aligned}
$$

$$
\begin{aligned}
& 68 \text { ميوان البحتري، تحقيق حسن كامل الصيرفي، مصر: دار المعارف، ج3، ص2002. } \\
& 69 \\
& 70
\end{aligned}
$$




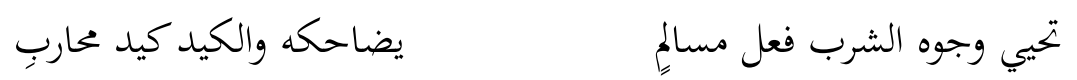

وحري بالشاعر المسلم أن يبتعد عن وصف العاهات والسوؤات، لما في ذلك من الحرمة من جهة، ولما

$$
\text { فيه من الإيذاء لأصحابها من جهة أخرى. }
$$

النسيب هو "ذكر خلق النساء وأخلاقهن، وتصرف أحوال الموى به معهن". 71 والنسيب هو من أكثر الأغراض الشعرية التي يجبها عامة الناس، فهو غرض وثيق الصلة بالنفوس وما فيها من خلجات.

ومن الشعراء من وصف المرأة وصفاً حسياً مثل عمر بن أبي ربيعة، ومنهم من وصفها متعففاً مثل الشعراء العذريين، ولأهمية هذا الغرض يذيع صيت شعرائه، وقد كان من عادة العرب أن يبتدئوا قصائدهم

والنسيب المتعفف ليس محرماً، فقد سمع الرسول صلى الله عليه وسلم لحسان وكعب وغيرها، ولم ينكر المقدمات الطليلة عليهم. قال العلامة الزبيدي:"فمن ذلك إنشاد كعب بن زهير بين يديه قصيدته اللامية، وفيها من التشبيب والمبالغات ما لا يخفى، ولم ينكر عليه ذلك". 72 وكذلك استمعت زوجته عائشة للنسيب، ففي الحديث عن مسروق قال: دخلت على عائشة رضي الله عنها، وعندها حسان بن ثابت ينشدها شعراً يشبب بأبيات له...".73وفي تعقيبه على قصيدة بانت سعاد يقول القرطبي: "فجاء في هذه القصيدة من الاستعارات والتشبيهات بكل بديع، والنبي صلى الله عليه وسلم يسمع ولا ينكر في تشبيهه ريقها بالراح". 74 وللفقهاء والعلماء غزل عفيف مبثوث في كتب السير والتراجم، ولكن مما يجدر التنبه إليه في تعاطي هذا اللون الشعري هو ضرورة اجتناب التشبيب بامرأة معينة، 75 أو ما يدل على معين، واجتناب العبارات

$$
\begin{aligned}
& 71 \\
& 7272 \\
& 7373 \\
& 74 \\
& 75
\end{aligned}
$$


والأوصاف التي هيج الغرائز الجنسية، واجتناب النسيب بالغلمان والمخثنين مطلقاً، فهو من أكبر المحرمات، 76 وقد داب بعض الصوفية على نقل هذه الأشعار الغزلية إلى معان دينية، زاعمين الحب والعشق للذات الإلهية من خلالها، فتراهم يطربون لدى إنشادها ويتواجدون، وهذا من أفرى الفرى، وقد حمل عليهم جار الله الزخشري حملة شديدة في تفسيره، مؤكداً حرمة ذلك. 77

وينبي عند تعاطي هذا اللون من الشعر رسم علاقة نزيهة بين الرجل والمرأة، في الإطار الذي ترضاه العقيدة، وتقبله الفطرة، من خلال العلاقة الزوجية فقط، وما أحسن قول مصطفى صادق الرافعي في هذا الصدد: 78

$$
\begin{aligned}
& \text { من للمحب ومن يعينه الحب أهنأه حزينه }
\end{aligned}
$$

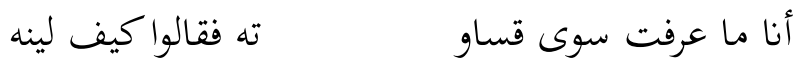

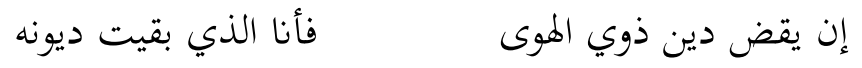

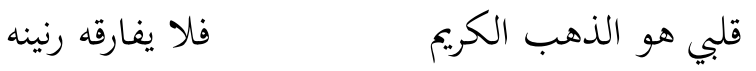

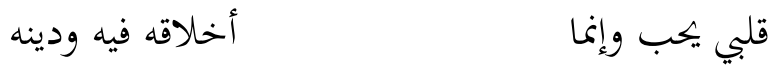

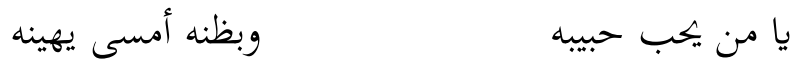

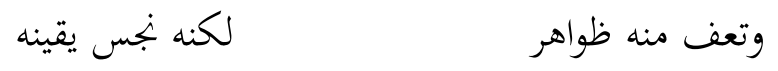

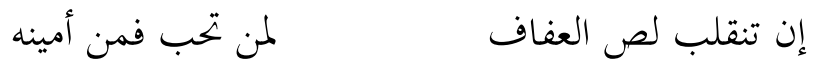

$$
\begin{aligned}
& 76 \text { تممد عمود الحجازي: التفسير الواضح، الزقازيق: دار التفسير، ج19، ص77، والزحيلي: التفسير المنير، مصدر سابق، ج19، } \\
& \text { ص248. } \\
& 77 \text { تفسير الكشاف، مصدر سابق، ج1، ص634. } \\
& 78 \text { 7 الدسوقي: في الأدب الحديث، دار الفكر العربي، ج2، ص290، صاف2 }
\end{aligned}
$$




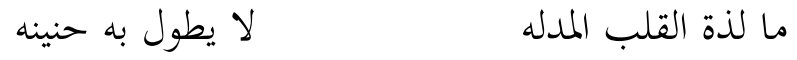

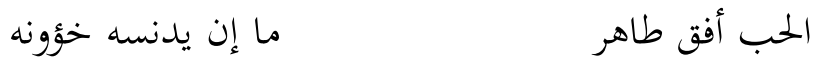

هكذا الحب.... طهارة وسمو وارتقاء... وليس علاقات مدنسة في الخفاء، 79 ومن النسيب المستحسن

قول ابن سنان الخفاجي:80

$$
\begin{aligned}
& \text { أتظن الورق في الأيك تغني أهما تضمر حزناً مثل حزني }
\end{aligned}
$$

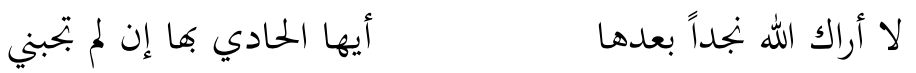

$$
\begin{aligned}
& \text { هل تباريني إلى بث الجوى ي ديار الحيّ نشوى ذات غصن }
\end{aligned}
$$

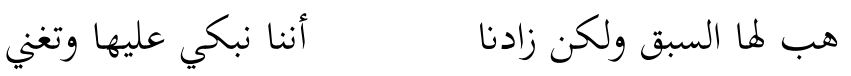

ومما يلحظ هنا قلة الشعر الإسلامي الحديث في هذا المضمار، وكأن الشعراء الإسلاميين شغلتهم قضايا الأمة الكبرى عن كل ما سواها، مما جعل الأجيال الناشئة تتداول دوايين شعراء اللهو والمجون في العصر الحديث، فضاعت الأخلاق، وتحلت القيم، والسؤال الذي يطرح نفسه الآن بإلحاح: لماذا لا نوجد البديل الصالح عن هذه الدواوين الحمراء التي تباع هنا وهناك... هل يجوز إهمال الجانب الهام في حياتنا الاجتماعية والعاطفية؟

\section{خامساً - شعر المراثي}

الرثاء مدح للميت، قال قدامة: "ليس بين المرثية والمدحة فصل إلا أن يذكر في اللفظ ما يدل على أنه لهالك، مثل: كان، وتولى، وقضى نحبه، وما أشبه ذلك". 81

$$
\begin{aligned}
& 79
\end{aligned}
$$

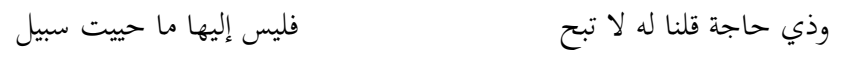

$$
\begin{aligned}
& \text { لنا صاحب لا ينبغي أن نخونه }
\end{aligned}
$$

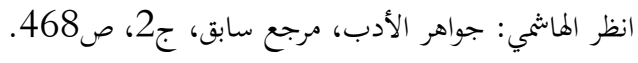

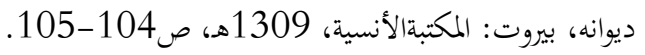


ولأن الرثاء هو مدح للميت، فما قلناه عن الضوابط في شعر المديح، يككن أن يقال هنا، ويكن

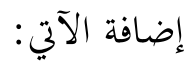

الإيمان بالقضاء والقدر، وأن الله هو الذي يجيي ويميت، ومن ثم يجب على الشاعر أن يجتنب كل عبارة فيها سب وقذف للدهر، وأنه خؤون يغتال الناس، فهذا كله مما يتناف مع العقيدة الإسلامية، وهو كثير

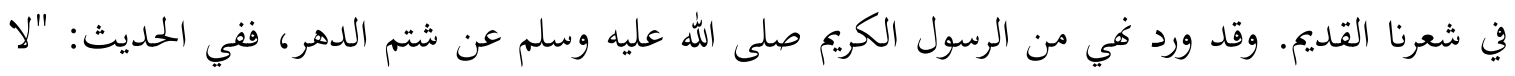

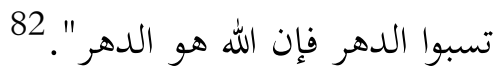

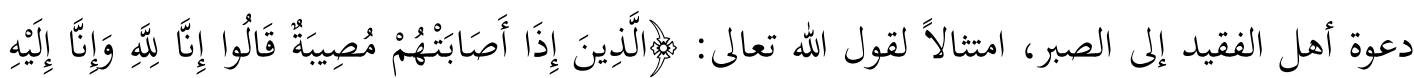

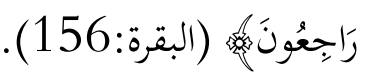

ذكر الآخرة والمعاد، وأن هذا مصير الإنسانية قاطبة، مهما امتد العمر وطال الأمل. قال الله تعلى:

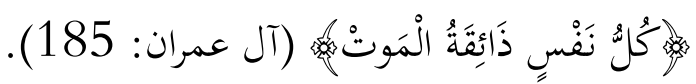

عدم الإسراف في تصوير التفجع والحزن، فليس مستساغاً قول المتبي مثلاً في رثاء عحمد بين إسحاق التنوخي:83

$$
\text { خرجوا به ولكل باكٍ خلفه صعقات موسى يوم دك الطور }
$$

وذلك لما في هذا البيت من المبالغة الشديدة التي تصور حزن القوم، ولكنها على أية حال لن تكون كصعقات موسى... ولذلك كانت هذه مبالغة ممجوجة.

عدم الإسراف في مدح الميت، وأنه جبل مضى وغو ذلك. مثلما فعل ابن الرومي في رثاء عحمد بن

$$
\text { نصر بن بسام حيث قال:84 }
$$

$$
\begin{aligned}
& 81 \\
& 82 \\
& 83 \\
& 84
\end{aligned}
$$




$$
\text { من لم يعاين سير نعش محمد لم يدر كيف تسير الأجبال }
$$

فمثل هذه المبالغات لا تفيد الميت، وقد تكون موضع مؤاخذة لدى الشارع الحكيم. ففي الحديث عن أبي موسى رضي الله عنه، قال: سمعت رسول الله صلى الله عليه وسلم يقول: ما من ميت يموت، فيقوم باكيهم فيقول: واجبلاه! واسيداه! ونحو ذلك، إلا وكل به ملكين يلهزانه، ويقولان: أهكذا كنت؟؟". 85 والآثار في هذا الباب كثيرة وختلفة، وجمع بينها العلامة علي القاري فقال: "والحاصل أن الميت إذا كان له تسبب في هذه المعصية ولو بتقصير في الوصية، أو رضي بهذه القضية، فالعذاب على حقيقته، وإلا فمحمول على تألمه، سواء عند نزعه أو موته، ويستوي فيه الكافر والمؤمن، وبهذا يجصل الجمع بين قوله تعالى: ومن الرثاء الإسلامي الصادق رثاء أبي ذؤيب الهذلي لأولاده، قال أبو زيد عمر بن شبة: "تقدم أبو ذؤيب جميع هذيل بقصيدته العينية التي يرثي فيها بنيه، يعني قوله:

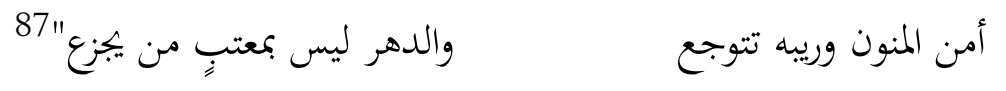

ومن عيون المراثي أيضاً، رثاء التهامي لولده، وفيها:88

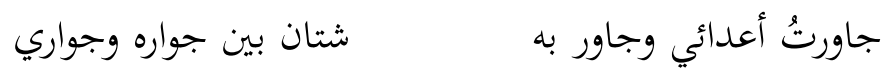

ولكن أفضل مرثية على الإطلاق هي مرثية حسان في النبي صلى الله عليه وسلم ومطلعها:89

$$
\text { بطيبة رسم للرسول ومعهد منير وقد تعفو الرسوم وقممد }
$$

85 8روه الترمذي، وقال حديث حسن غريب، وهو من أحاديث مشكاة المصابيح. انظر المرقاة مع المشكاة، مصدر سابق، ج4، ص235.

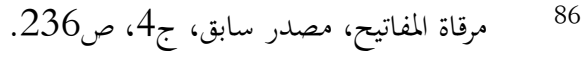
87

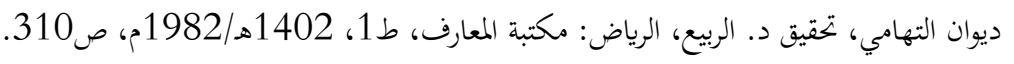


قدمنا فيما سبق بعض الضوابط الشرعية للأغراض الشعرية، ونرجو أن نكون قد وفقنا في ذلك: ففي شعر المديح يجب إخلاص النية له تعالى، ومدح الإنسان بما فيه والبعد عن الإسراف والمبالغة، والتركيز على الصفات المحمودة، وتقديم الفضائل الإنسانية والدينية على الفضائل الجسمية والمادية للممدوح، وبيّنا أن الفخر هو فرع من فن المديح، وأنه ليس من ديدن المسلم الذي شيمته التواضع، ولكنه قد يكون مطلوباً في مواطن الحرب، أو لإظهار أنعمُ الله تعالى، والتحدث بها بما لا يورث الغرور والكبرياء. وفي شعر الهجاء ينبغي عدم هجاء الصفات الجسدية التي جعلها الله ملازمة للإنسان، وإنما هجاء الصفات النفسية من شره وجبن وكفر ونو ذلك، وأن لا يكون الهجاء سبيلاً للافتراء على الآخرين، ويجب أن يقتصر على أهل الكفر المحابين أو أهل الزندقة والإلحاد في المجتمع الإسلامي أو المجاهرين بالفسق والمعصية.

وفي شعر الوصف بيّنا أن الكون كتاب صامت يشهد على قدرة الخالق المبدع عز وجل، ووظيفة الشاعر أن يبرز الآيات المبثوثة للناس في كل شيء، وأن يبتعد عن وصف المحرمات وصفاً يغري بها مثل برل الحمرة ونوها من الموبقات.و كذلك يبتعد عن وصف العورات والسوءات، ويجعل ما يصفه في محراب

$$
\text { الطبيعة أو بدائع العمران من قصور وتحف أنمودجات للآخرة. }
$$

وفي شعر النسيب بيّنا أن النسيب العفيف مسموح به، ولكن الإسلام يرفض النسيب الصارخ الذي يستير الغرائز ويهيج الشهوات، كما يرفض الغزل بامرأة معينة، ويحرم الغزل بالذكور فهائياً.

وفي شعر المراثي بينّا أن الشاعر يجب عليه أن يذكر الناس بثوابت الإيمان، وبالقضاء والقدر، ويبتعد

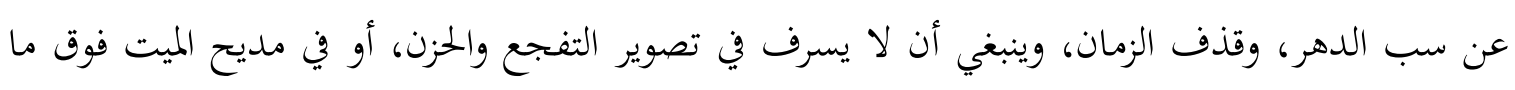
يستحقه.

وهذه الضوابط مهمة للشاعر المسلم في العصر الحديث، ويجب مراعاتما في نتاجه كله، حتى يكون ما يقوله من شعر منسجماً مع رسالة الإسلام، ومحققاً لأغراضه العظيمة وقيمه الخالدة، مؤكدين أهمية التزام 
الشاعر المسلم بدينه وقيمه، وأن لا يطلق الكلام علعنانه، بل يعد نفسه مسؤولاً عن كل كلمة يقولها أمام لله

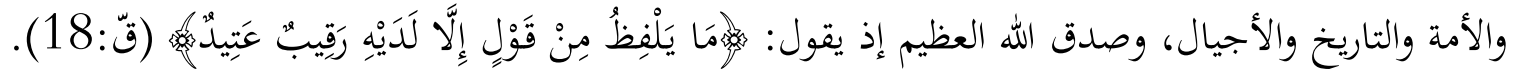

